\title{
Shunt-dependent hydrocephalus: management style among members of the American Society of Pediatric Neurosurgeons
}

\author{
Mark R. Kraemer, MD, Carolina Sandoval-Garcia, MD, Taryn Bragg, MD, and \\ Bermans J. Iskandar, MD \\ Department of Neurosurgery, University of Wisconsin Hospitals and Clinics, Madison, Wisconsin
}

OBJECTIVE The authors conducted a survey to evaluate differences in the understanding and management of shuntdependent hydrocephalus among members of the American Society of Pediatric Neurosurgeons (ASPN).

METHODS Surveys were sent to all 204 active ASPN members in September 2014. One hundred thirty responses were received, representing a $64 \%$ response rate. Respondents were asked 13 multiple-choice and free-response questions regarding 4 fundamental problems encountered in shunted-hydrocephalus management: shunt malfunction, chronic cerebrospinal fluid (CSF) overdrainage, chronic headaches, and slit ventricle syndrome (SVS).

RESULTS Respondents agreed that shunt malfunction occurs most often as the result of ventricular catheter obstruction. Despite contrary evidence in the literature, most respondents $(66 \%)$ also believed that choroid plexus is the tissue most often found in obstructed proximal catheters. However, free-text responses revealed that the respondents' understanding of the underlying pathophysiology of shunt obstruction was highly variable and included growth, migration, or adherence of choroid plexus, CSF debris, catheter position, inflammatory processes, and CSF overdrainage. Most respondents considered chronic CSF overdrainage to be a rare complication of shunting in their practice and reported wide variation in treatment protocols. Moreover, despite a lack of evidence in the literature, most respondents attributed chronic headaches in shunt patients to medical reasons (for example, migraines, tension). Accordingly, most respondents managed headaches with reassurance and/or referral to pain clinics. Lastly, there were variable opinions on the etiology of slit ventricle syndrome (SVS), which included early shunting, chronic overdrainage, and/or loss of brain compliance. Beyond shunt revision, respondents reported divergent SVS treatment preferences.

CONCLUSIONS The survey shows that there is wide variability in the understanding and management of shunt-dependent hydrocephalus and its complications. Such discrepancies appear to be derived partly from inconsistent familiarity with existing literature but especially from a paucity of high-quality publications.

https://thejns.org/doi/abs/10.3171/2017.2.PEDS16265

KEY WORDS hydrocephalus; shunt failure; slit ventricle syndrome; CSF overdrainage; headache; survey

S HUNT-DEPENDENT hydrocephalus accounts for a significant segment of a pediatric neurosurgical practice. Despite remarkable advances in technology since the first cerebrospinal fluid (CSF) shunt was implanted, shunt failure and shunt-related morbidity remain major public health challenges..$^{16,21,26}$ These difficulties are coupled with controversies regarding the pathophysiology of these complications and differences in management styles among surgeons. The aim of the present study was to evaluate differences in shunt-dependent hydrocephalus philosophies and management styles among experienced North American surgeons. Accordingly, we surveyed members of the American Society of Pediatric Neurosurgeons (ASPN) to outline these differences using a targeted questionnaire. The ASPN is the leading pediatric neurosurgical society in North America (https://www.aspn.org/),

ABBREVIATIONS ASD = antisiphon device; ASPN = American Society of Pediatric Neurosurgeons; $C S F$ = cerebrospinal fluid; ETV = endoscopic third ventriculostomy; $I C P=$ intracranial pressure; $L P=$ lumboperitoneal; OSV = Orbis-Sigma valve; $S V S=$ slit ventricle syndrome.

ACCOMPANYING EDITORIAL See pp 213-215. DOI: 10.3171/2017.3.PEDS17103.

SUBMITTED May 12, 2016. ACCEPTED February 24, 2017.

INCLUDE WHEN CITING Published online June 30, 2017; DOI: 10.3171/2017.2.PEDS16265. 
whose membership exclusively comprises board-certified (American Board of Neurological Surgery) neurosurgeons with predominantly pediatric practices. Although the data are not generalizable to neurosurgeons with a large adult practice or to younger pediatric neurosurgeons, the survey arguably represents the practices of the field leaders. Furthermore, the survey is not intended to inform current practice. Rather, variations in understanding and clinical practice highlight important areas of uncertainty in shuntdependent hydrocephalus care, which may inform further studies and registries. This study focuses on 4 problems encountered in shunt-dependent hydrocephalus management: shunt malfunction, chronic headaches, shunt overdrainage, and slit ventricle syndrome (SVS).

\section{Methods}

An email was sent to all 204 active members of the ASPN on September 15, 2014. The email included a link to the survey and a short description of the purpose of the study. The questionnaire was designed and maintained using the UW-Madison Qualtrics Hosting Service. Qualtrics survey software was used to distribute and collect response data. One reminder email was sent to those who had not yet completed the survey 2 weeks after the original distribution. Links to the online survey were active for 2 months. Participation in the survey was voluntary, and data were de-identified prior to analysis. A total of 130 surgeons completed the survey, for an overall response rate of $64 \%$. The majority of surveys were completed after the first email distribution. Few respondents (13\%) submitted their responses after the second distribution. Given the challenges in surveying physicians, the overall response rate was considered appropriate. ${ }^{9}$ Participants were asked 13 multiple-choice and free-response questions within the categories of shunt malfunction, chronic headaches, shunt overdrainage, and SVS. Optional freetext boxes were included for nearly all questions. Freetext answers were included in categorical groupings where appropriate or were considered separately. To increase survey speed and compliance, individual responses were not mandatory for Likert scale, multiple-selection, or free-response questions. Thus, the collected data represent fewer than $100 \%$ of respondents for some categories (for example, in Question 8, 7 respondents did not indicate the likelihood of stress as a contribution to headache in patients with shunts). Response rates for these questions are shown. Survey logic was employed in only one instance: In Question 6, under "Replace valve" as a CSF overdrainage treatment, respondents selecting "Never" were not shown Question 7, which inquired about specific valve preference. Basic descriptive statistics were used to analyze respondent data. The complete survey is available as Supplementary Material.

\section{Results}

\section{Management of Shunt Malfunction}

The ASPN surgeons who answered the survey prefer 3 varieties of shunt valves: $41 \%$ primarily use differential pressure valves, $29 \%$ use differential pressure valves with an antisiphon device (ASD), and $27 \%$ mostly use programmable valves. A small percentage of surgeons (3\%) prefer the flow-regulating Orbis-Sigma valve (OSV or OSV-II) as their primary choice (Fig. 1).

The majority of respondents (98\%) agree that obstructive shunt failure occurs most commonly at the ventricular catheter, although a few (2\%) report a higher incidence of distal catheter obstruction. Surgeons were then asked what, in their experience, was the most common source of ventricular catheter obstruction among those cited in the literature, that is, CSF debris, choroid plexus, ventricle collapse, and loculations. Most respondents (66\%) consider ingrowth of the choroid plexus to be the most common cause of proximal shunt obstruction, whereas $18 \%$ favor CSF contents (for example, blood, cellular debris), 8\% ventricular collapse, and $<1 \%$ loculations (Table 1). Ten surgeons reported other sources of ventricular obstruction: ependymal or scar tissue (8 respondents), undetermined cellular ingrowth (1 respondent), or some combination of the above categories (1 respondent). One surgeon reported uncertainty.

A total of 109 surgeons offered their opinions in freetext format regarding the most likely underlying cause of ventricular obstructions. These fell into 6 general categories: 1) small ventricle size, 2) catheter position, 3) choroid plexus migration or adherence, 4 ) siphoning or overdrainage, 5) accumulation of CSF debris, and 6) reactive or inflammatory processes. Several of these explanations fit into multiple domains. The most commonly cited explanation for proximal shunt obstruction involved adherence, growth, or migration of choroid plexus (41 comments), followed by siphoning or overdrainage (32 comments), poor catheter position ( 25 comments), and/or small ventricles (22 comments). Few surgeons cited CSF debris (12 com-

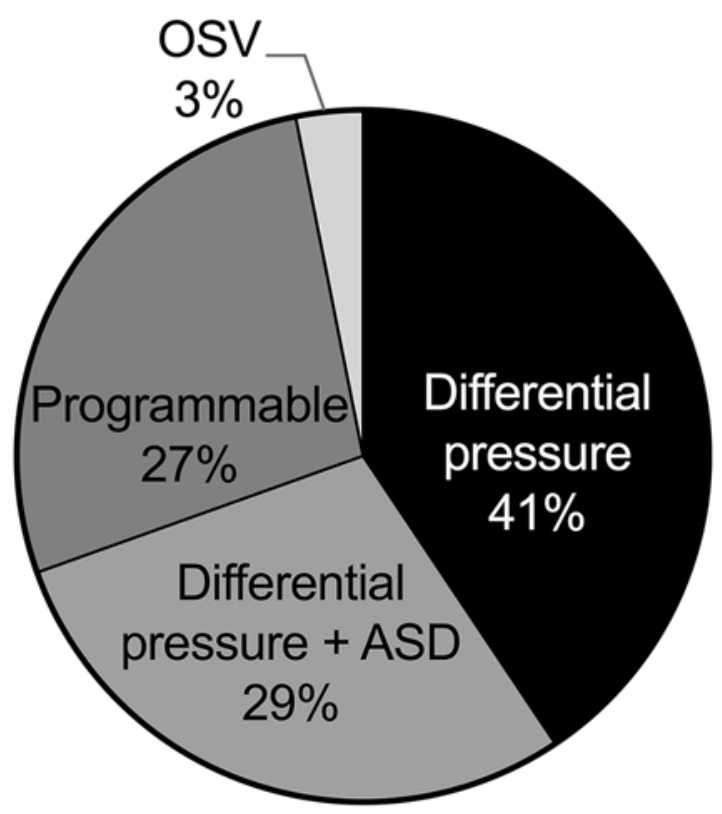

FIG. 1. Primary shunt valve preference. The respondents reported which valve they predominantly use. Multiple-choice options included differential pressure valve, differential pressure valve with ASD, programmable valve, and flow-regulating OSV. 
TABLE 1. Source of proximal shunt obstruction

\begin{tabular}{lcc}
\hline \multicolumn{1}{c}{ Obstruction Source } & No. & $\%$ \\
\hline Ingrowth of choroid plexus & 86 & 66 \\
\hline CSF debris & 23 & 18 \\
\hline Ventricular collapse & 10 & 8 \\
\hline Loculations & 1 & $<1$ \\
\hline Other & 10 & 8 \\
\hline
\end{tabular}

Respondents were asked their opinion about the most likely source of proximal shunt obstructions. Ten surgeons cited other causes in an optional free-text box, which included ependyma, scar tissue, or cellular ingrowth of unknown origin.

ments) or reactive/inflammatory processes (5 comments) as the most likely cause. Representative free-text descriptions are shown in Table 2.

\section{Management of Chronic Shunt Overdrainage}

When asked to estimate the rate of chronic shunt overdrainage in their practices, most respondents $(86 \%)$ reported that no more than $15 \%$ of their patients suffer from it (Fig. 2). Estimates ranged from $0 \%$ to $75 \%$, with a median of $5 \%$.

If a diagnosis of chronic overdrainage was made, most respondents reported managing the problem with a combination of shunt valve replacement for pressure incompatibility, addition of ASDs, or valve-setting adjustments (Fig. 3). Specifically, $45 \%$ of respondents reported often or always placing an ASD, $41 \%$ reported adjusting valve settings, and $30 \%$ reported replacing the valve. Fifty percent of surgeons who reported replacing the valve primarily used programmable valves with or without an ASD, although differential pressure with ASD (25\%) and OSV (19\%) were also popular valve choices (Fig. 4). Few surgeons $(3 \%)$ said they use differential pressure valves alone. A small number reported placing a shunt assistant (2 respondents) or distal slit catheter (1 respondent). Overall, abdominal binders and placement of an additional valve or

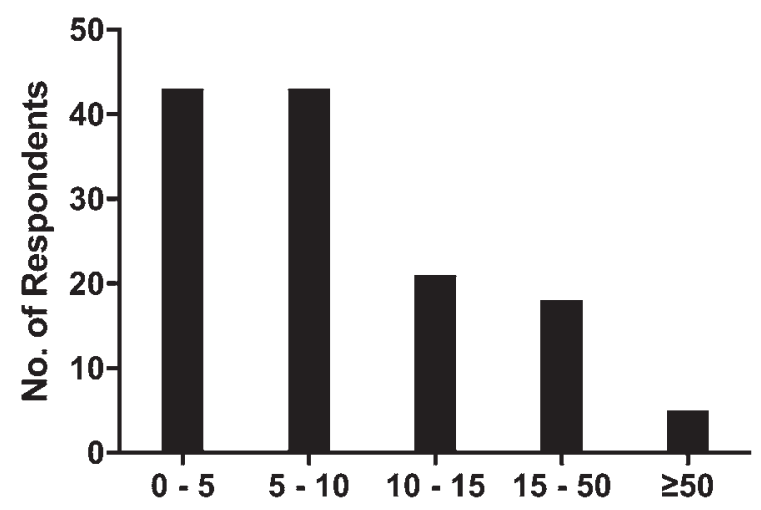

Estimated percentage of patients with overdrainage

FIG. 2. Prevalence of chronic shunt overdrainage. Respondents estimated the approximate percentage of patients in their practice with chronic shunt overdrainage. Responses were collected as any number between 0 and 100 . Categorized estimates are shown, which range from $0 \%$ to $75 \%$, with a median of $5 \%$.

shunt assistant are unpopular overdrainage management strategies with more than two-thirds of surgeons reporting never or rarely using them (Fig. 3).

In an optional free-response box, some respondents suggested treating overdrainage by other methods, including cranial expansion (4 respondents) and endoscopic third ventriculostomy (ETV; 2 respondents). Moreover, in the optional free-response section, 3 surgeons expressed concerns about the definition of overdrainage. For example, one suggested that absolute overdrainage that results in postural headaches and subdural collections is rare and should be distinguished from the relative overdrainage that predisposes to SVS. However, others doubted whether shunt overdrainage exists at all (2 respondents).

\section{Management of Chronic Headaches in Shunt Patients}

The ASPN surgeons most often attribute chronic headaches in shunt patients to medical reasons, for example,

TABLE 2. Pathophysiology of proximal shunt obstruction

\begin{tabular}{|c|c|}
\hline Explanation & Representative Free-Text Answer \\
\hline Small ventricular size & $\begin{array}{l}\text { "Associated with ventricles getting smaller and wall sticking to catheter, blocking holes;" "As the ventricle be- } \\
\text { comes smaller, the relative proximity of choroid to the shunt catheter becomes closer" }\end{array}$ \\
\hline Siphoning/overdrainage & $\begin{array}{l}\text { "Ventricular wall collapses around the ventricular catheter holes;" "Negative pressure sucks choroid into catheter } \\
\text { where it grows" }\end{array}$ \\
\hline $\begin{array}{l}\text { Choroid plexus growth, migration, } \\
\text { or adherence }\end{array}$ & $\begin{array}{l}\text { "Choroid plexus mobility and approximation to aperture in shunt catheter;" "The choroid plexus is very apt to grow } \\
\text { into a catheter. In a growing child, even if we place a catheter away from the choroid plexus, with growth of the } \\
\text { brain it may migrate into the plexus" }\end{array}$ \\
\hline Cellular debris & $\begin{array}{l}\text { "Progressive closure of holes over time due to flow related debris;" "Cellular debris in most cases. Obstruction } \\
\text { seems to occur less frequently if catheter does not contact parenchyma..." }\end{array}$ \\
\hline Catheter position & $\begin{array}{l}\text { "Catheter holes, initially or over time, are positioned in proximity to choroid plexus;" "Poor placement of the } \\
\text { ventricular catheter tip" }\end{array}$ \\
\hline Inflammatory process & $\begin{array}{l}\text { "The shunt is a foreign body and is walled off with scar tissue as it comes into contact with choroid plexus or } \\
\text { ependyma;" "Perhaps body reaction to foreign body" }\end{array}$ \\
\hline
\end{tabular}

One hundred nine respondents offered opinions about proximal shunt obstruction pathophysiology in free-text format. These were divided into 6 general categories: small ventricular size; siphoning or overdrainage; choroid plexus growth, migration, or adherence; cellular debris; poor catheter position; and reactive or inflammatory processes. Representative free-text explanations are shown for each category. 


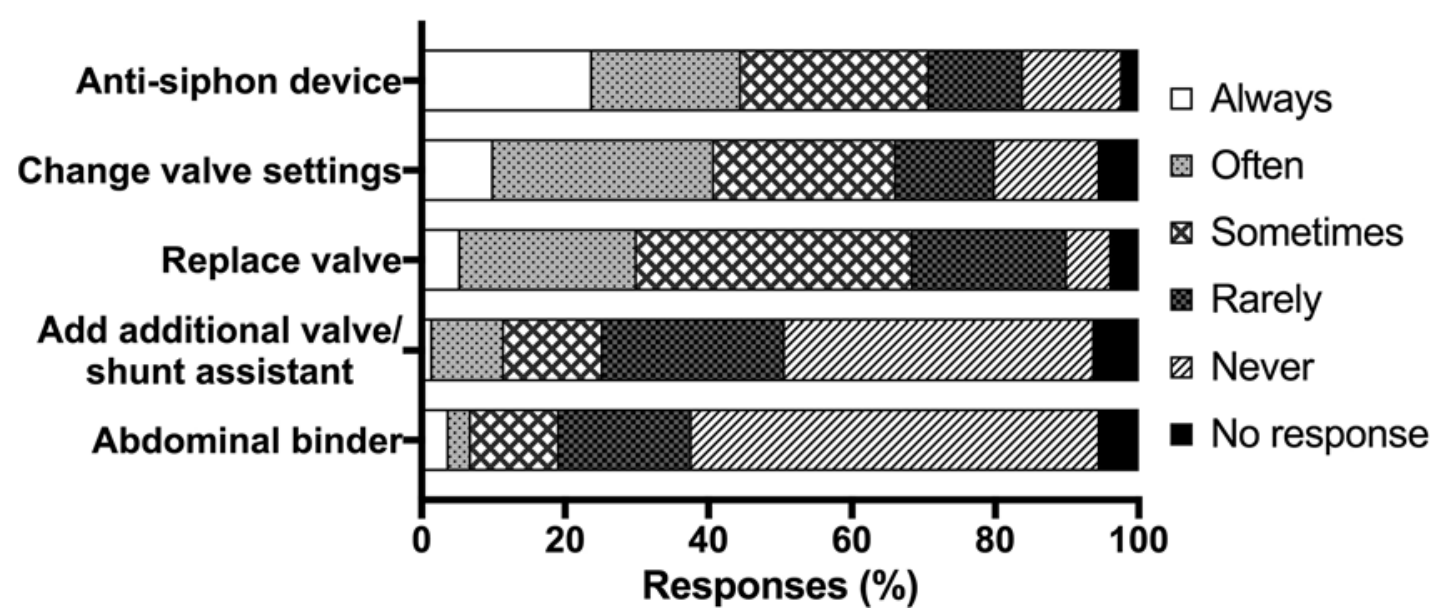

FIG. 3. Treatment of chronic shunt overdrainage. Respondents were asked about their preferred treatment for chronic shunt overdrainage. Response rate was $95 \%-98 \%$.

tension or migraine. Forty-nine percent of respondents considered these reasons "very likely" or "extremely likely." Stress, CSF underdrainage, and CSF overdrainage were not considered likely causes, with $18 \%$ or fewer respondents considering them "very likely" or "extremely likely" (Fig. 5). Overall, however, respondents seemed to consider overdrainage a more likely etiology of chronic headaches than underdrainage. Other offered explanations included altered CSF or vascular dynamics (5 comments). These included CSF pulsation absorption, hyperpulsatility in microvascular flow, and poor physiological match of the shunt to intracranial pressure (ICP) pulsations.

When shunt patients present with chronic headaches,

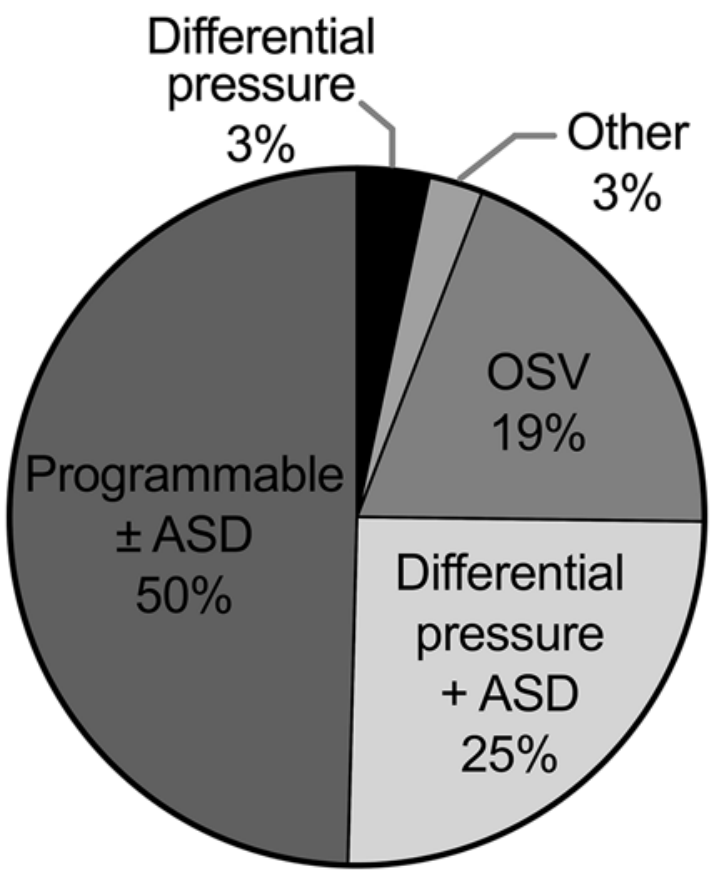

FIG. 4. Valve preference for chronic shunt overdrainage. Surgeons who reported treating chronic CSF overdrainage with valve replacement (119 [92\%] of 130) were asked their valve preference. most ASPN surgeons provide reassurance (51\% "often" or "always"). Referral to a pain clinic is also used (24\% "often" or "always;" Fig. 6). More aggressive measures such as shunt revision and valve replacement are less popular, with $65 \%$ and $57 \%$ of surgeons reporting "rarely" or "never" using those strategies, respectively. In an optional freetext box, 25 surgeons (19\%) reported that they offer ICP monitoring to these patients. Surgeons also mentioned referral to neurology or headache clinics (18 respondents [14\%]) and the use of other imaging studies to ensure shunt patency (7 respondents [5\%]).

\section{Slit Ventricle Syndrome}

For the purposes of this study, SVS was defined as "symptomatic intermittent ICP elevation with small ventricles," as stated in the survey prior to all the SVS-related questions. Beyond patient history and imaging studies, $51 \%$ of respondents said they "often" or "always" diagnose SVS with the assistance of prolonged ICP monitoring (Fig. 7). Shunt tap and lumbar puncture are less commonly employed. In the optional free-response box, 5 surgeons suggested shunt exploration surgery. Four respondents suggested specific imaging studies, for example, CSF flow studies.

To assess SVS treatment methodology, participants were given a list of treatment options and asked to select all the procedures they perform. An optional free-text box was also provided for respondents to add treatments not listed. In an effort to understand general treatment strategy for patients with SVS, participants were then asked to rank the treatments they selected from most often to least often used.

The most commonly selected treatments for managing patients with SVS among 127 respondents included ventriculoperitoneal shunt revision (88\%), cranial expansion (57\%), addition of an ASD (53\%), and ETV (42\%). The least popular treatments were placement of an additional valve or shunt assistance device (30\%), placement of a lumboperitoneal (LP) shunt (25\%), and abdominal binder (16\%; Table 3). Other treatments included in the optional free-text box generally fit into the above catego- 


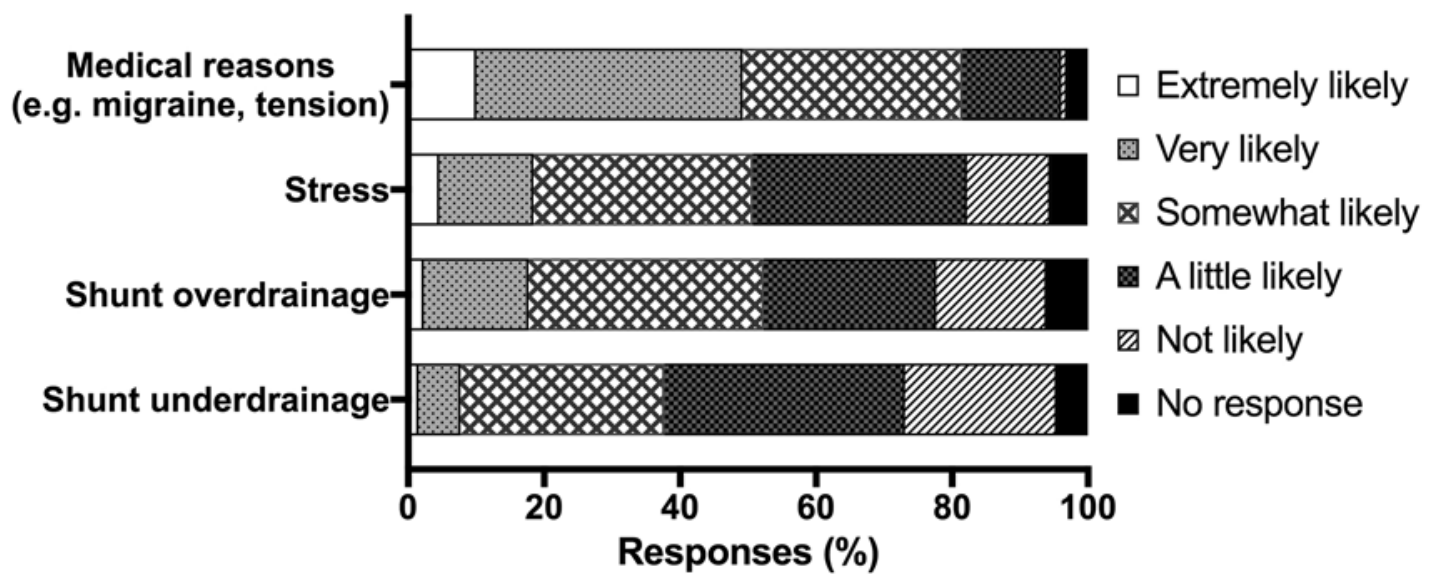

FIG. 5. Causes of chronic headaches. Respondents were asked the most likely reasons for chronic headaches in patients with shunts. Response rate was $94 \%-97 \%$ for each category.

ries, although 2 surgeons included medical treatments (for example, propranolol) in their registry of SVS treatments. The corresponding ranking of each treatment approach, compared with other treatments specific to each respondent, is also shown in Table 3.

Treatment methodology is shown in Table 4. Among surgeons who elect to revise the shunt for SVS, $62 \%$ rank it as their first-line treatment approach. Other first-line approaches include medical management ( 2 respondents) and cisternal catheter placement ( 2 respondents). Placement of an ASD is most often used as second-line therapy (34\%). Endoscopic third ventriculostomy and cranial expansion are less commonly used. Among surgeons performing ETV, 28\% rank it as third line, closely followed by cranial expansion (24\%). When 4 or more treatments were selected (53 respondents), cranial expansion was the only significant fourth-line treatment $(42 \%)$. Other treatments such as LP shunting, placement of an additional valve or shunt assistant, and abdominal binders are not significant first-, second-, third-, or fourth-line treatments as they were selected by fewer than $16 \%$ of respondents across each of these categories.

Survey participants were also asked why they think
SVS occurs. Free-text responses from 98 respondents were reviewed and categorized. Responses generally fell into 4 groups: chronic CSF overdrainage ( 42 comments), abnormal brain compliance (35 comments), small skull size (22 comments), and shunt placement early in life (18 comments). Individual responses often fit into multiple domains. Table 5 shows representative free-text responses within each of these categories. Other comments included poor shunt valve design, altered venous pressure or compliance, abnormally elevated ICP pulsation, and ventricular adhesions.

\section{Discussion}

\section{Shunt Obstruction}

Shunt obstruction is the most common problem encountered in the care of the patient with hydrocephalus. Prospective studies have shown shunt failure rates of up to $40 \%$ after 1 year and $50 \%$ after 2 years. ${ }^{16}$ Randomized controlled trials have demonstrated no difference in shunt longevity when the most commonly used valve types were compared ${ }^{1,8,16}$ Consistent with the lack of evidence for a superior shunt valve, surgeons of the ASPN are equally

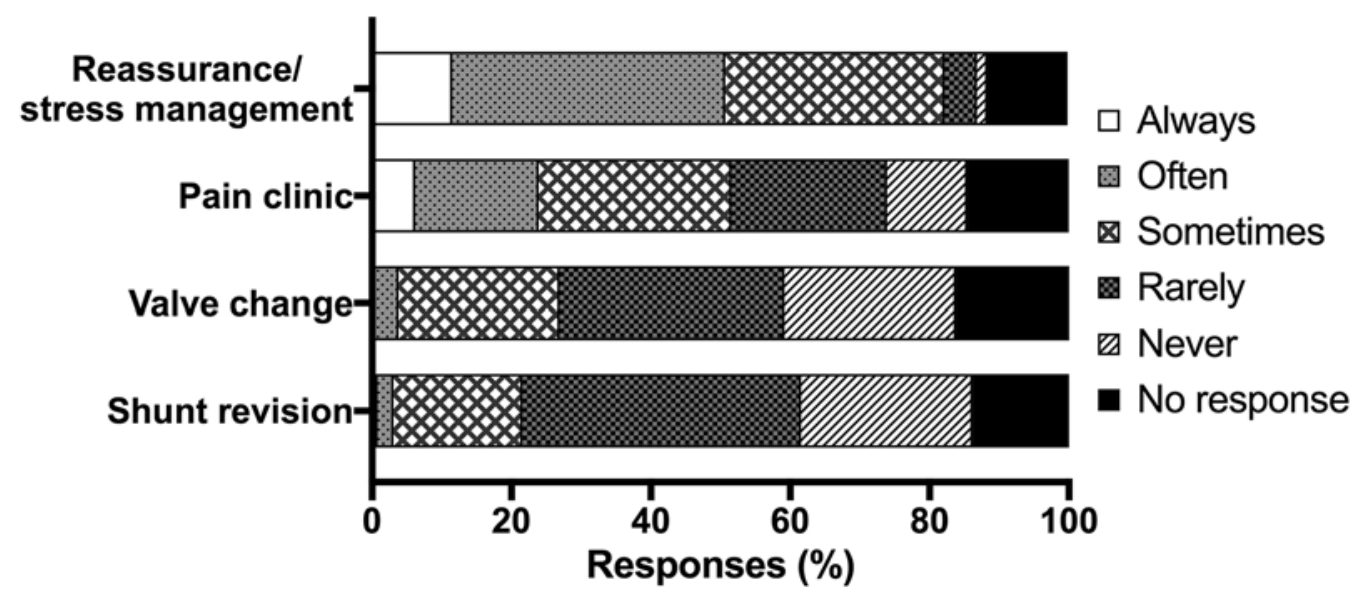

FIG. 6. Treatment of chronic headaches. Respondents were asked how often they use each of the reported treatment strategies to manage chronic headaches in shunt patients. Response rate was $84 \%-88 \%$ for all categories. 


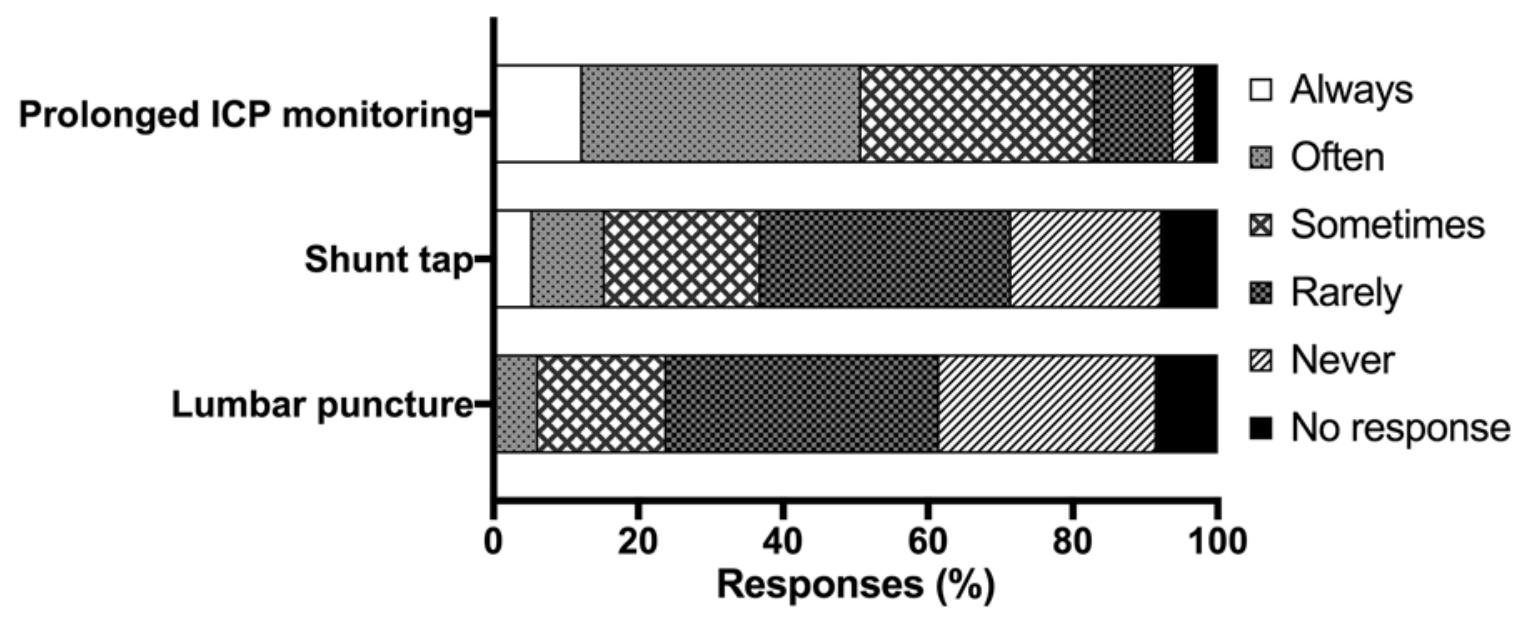

FIG. 7. Tests used to diagnose SVS. Respondents were asked which diagnostic tests they employ to confirm the diagnosis of SVS (in addition to history and imaging studies). Response rate was $92 \%-97 \%$ for all categories.

divided among 3 varieties of shunt valves: differential pressure valve, differential pressure valve with ASD, and programmable valve.

According to prospective studies, most shunt malfunctions are due to obstruction at the level of the ventricular catheter. ${ }^{8,15,16}$ Other well-known, noninfectious causes of shunt malfunction include mechanical failure, CSF overand underdrainage, ventricular loculations, and drainage site complications. ${ }^{3,4}$ Our survey data are consistent with the literature suggesting that proximal obstruction accounts for most shunt malfunctions. However, survey respondents provide different explanations for such obstruction. While most $(66 \%)$ consider choroid plexus to be the most common source of obstruction, a significant number of respondents (18\%) consider CSF debris to be the main cause. Few respondents favored other causes. Free-text explanations of the underlying pathophysiology are similarly distributed, with many respondents citing adherence, growth, or migration of the choroid plexus, often in combination with poor catheter positioning or CSF siphoning.

\section{TABLE 3. Treatment of SVS}

\begin{tabular}{lrrc}
\hline \multicolumn{1}{c}{ SVS Treatment } & No. & $\%$ & Average Ranking (SD) \\
\hline Revise VP shunt & 112 & 88 & $1.58(1.09)$ \\
\hline Cranial expansion & 72 & 57 & $3.37(1.29)$ \\
\hline Add ASD & 67 & 53 & $2.12(0.90)$ \\
\hline ETV & 53 & 42 & $2.85(1.00)$ \\
\hline $\begin{array}{l}\text { Add additional valve/ } \\
\quad \text { shunt assistant }\end{array}$ & 38 & 30 & $2.26(1.06)$ \\
\hline $\begin{array}{l}\text { LP shunt } \\
\text { Abdominal binder }\end{array}$ & 32 & 25 & $3.34(1.23)$ \\
\hline
\end{tabular}

$\mathrm{VP}=$ ventriculoperitoneal.

Respondents were asked their preferred treatment modality for SVS. Among the options selected, respondents ranked them from most often to least often used. Average ranking and standard deviation for each treatment are shown. Three respondents selected no treatment, leading to an overall response rate of $98 \%$.
Classically, the choroid plexus is cited as the dominant tissue obstructing the proximal catheter, a notion based on several early histological observations. ${ }^{6,11}$ However, subsequent work has demonstrated that proximal shunt obstructions are primarily related to a variety of biological materials that lodge in ventricular catheters including, but not limited to, ependyma, connective tissue, neural tissue, macrophages, multinucleated giant cells, and aggregates of blood cells or debris.,17,23 In turn, clinical reports have shown that the choroid plexus is responsible for only a minority of ventricular catheter obstructions..$^{2,22,24}$ More recently, researchers investigating the underlying pathophysiology of proximal shunt obstruction have proposed a reactive and/or inflammatory process occurring in response to the foreign catheter material. ${ }^{12-14}$ Respondent opinions are inconsistent with these data. Among 109 free-text explanations, only 5 surgeons cited reactive or inflammatory processes as the most likely cause of proximal catheter obstruction.

TABLE 4. SVS treatment methodology

\begin{tabular}{|c|c|c|c|c|}
\hline SVS Treatment & First-Line & Second-Line & Third-Line & Fourth-Line \\
\hline Revise VP shunt & $76(62)$ & $24(22)$ & $6(7)$ & $5(9)$ \\
\hline Add ASD & $13(10)$ & $38(34)$ & $12(14)$ & $1(2)$ \\
\hline ETV & $5(4)$ & $12(11)$ & $24(28)$ & $8(15)$ \\
\hline Cranial expansion & $5(4)$ & $14(13)$ & $21(24)$ & $22(42)$ \\
\hline $\begin{array}{l}\text { Additional valve/ } \\
\text { shunt assistant }\end{array}$ & $10(8)$ & $14(13)$ & $9(10)$ & $4(8)$ \\
\hline LP shunt & $2(2)$ & $6(5)$ & $10(11)$ & $8(15)$ \\
\hline Abdominal binder & $6(5)$ & $2(2)$ & $4(4)$ & $5(9)$ \\
\hline Other & $6(5)$ & $1(1)$ & $1(1)$ & $0(0)$ \\
\hline Total & 123 & 111 & 87 & 53 \\
\hline
\end{tabular}

Values represent the number (percentage) of surgeons ranking each intervention as their first, second, third, or fourth utilized treatments for SVS. Treatments used most often within each tier appear in boldface type. Seven respondents did not select or rank any treatment, leading to an overall response rate of $95 \%$. 
TABLE 5. Causes of SVS

\begin{tabular}{lc}
\hline \multicolumn{1}{c}{ Explanation } & Representative Free-Text Answers \\
\hline CSF overdrainage & $\begin{array}{c}\text { "Chronic overdrainage of vents by shunt. Not enough resistance in valve as baby ages and AF [anterior fontanelle] } \\
\text { closes;" "Chronic overdrainage with intermittent ventricular catheter malfunction" }\end{array}$ \\
\hline Abnormal brain compliance & $\begin{array}{r}\text { "Decrease in ventricular size to slit with poor compliance;" "Bad karma. Or...yet to be understood factors during the } \\
\text { developmental years create a very noncompliant or 'stiff' brain" }\end{array}$ \\
\hline Small skull size & $\begin{array}{c}\text { Chronic overdrainage leading to the ventricles and skull being too small;" "Overdrainage at young age resulting in } \\
\text { inadequate intracranial volume" }\end{array}$ \\
\hline Shunt placement early in life & $\begin{array}{c}\text { "Shunting early in life particularly seen in premature;" "Unexplained changes in brain compliance related to chronic } \\
\text { shunting" }\end{array}$ \\
\hline
\end{tabular}

Ninety-eight respondents offered free-text explanations for SVS. These fell into 4 general categories: CSF overdrainage, abnormal brain compliance, small skull size, and shunt placement early in life. Representative responses are shown.

\section{Chronic CSF Overdrainage}

Shunt overdrainage is another well-known complication of shunt-dependent hydrocephalus. ${ }^{5}$ Although acute shunt overdrainage is a recognized but uncommon CSF shunt complication, our survey aims to investigate current understandings of chronic overdrainage. Most respondents consider chronic overdrainage a rare problem among their patients, while a few contend that most of their patients suffer from it. Reports in the literature suggest that about $10 \%$ of patients suffer from overdrainage. ${ }^{16,18}$ More than half of the survey respondents' estimates are well below this figure. These discrepancies could be attributed to differences in definition and diagnosis. For example, some surgeons may use more stringent criteria to define overdrainage, such as the presence of specific symptoms (for example, positional headaches) or radiographic findings (for example, subdural hematomas).

Despite the lack of evidence for valve superiority in treating shunt overdrainage, ${ }^{1}$ many surgeons elect to replace or adjust the shunt hardware in patients suffering from this condition. In this context, respondents tend to use predominantly programmable and flow-regulating valves. However, given the apparent variability in the definition and diagnosis of overdrainage, the results are difficult to interpret and highlight the need to develop better classifications to describe this problem.

\section{Chronic Headaches in Shunt Patients}

Patient surveys demonstrate a startlingly high prevalence of severe headaches among those with CSF shunts ( $29 \%$ of children and $42 \%-44 \%$ of adolescents and young adults), ${ }^{21}$ but few studies have investigated the pathophysiology of this challenging problem. Results of the present survey show that surgeons consider medical reasons to be the most likely cause of chronic headaches in this patient population. Yet, there is no evidence in the literature to support this contention. Moreover, despite suggestions in the literature that have linked headaches to CSF overdrainage, $, 10,18,20,25$ our survey data show that most surgeons do not consider this a likely cause. Interestingly, several surgeons suggest that changes in CSF flow dynamics, particularly pulsatility, are responsible for the headaches.

General headache treatment strategies among the respondents are consistent with opinions about headache etiology, with reassurance and referral to neurology or pain clinics being the most common practice. Aggressive invasive and surgical (shunt-related) measures to address headaches have been suggested by some authors ${ }^{20,21}$ but were uncommon among survey respondents. Considering that the incidence of headaches in the shunt patient population is probably much higher than average ${ }^{21}$ it is troubling that no evidence-based methods exist to address this problem. Furthermore, although medical and psychosocial interventions may be effective in the non-shunt population, it is unclear if such interventions succeed in shunt patients. It is also logical to assume that surgeons at medical centers with comprehensive headache clinics are more likely to develop referral patterns to multidisciplinary headache clinics than surgeons at centers lacking these services. Still, no evidence-based methods exist to address headaches in shunt patients. While the present survey does provide a rigorous comparison of general management strategies among survey participants, it raises important questions to address in future studies.

\section{Slit Ventricle Syndrome}

Slit ventricle syndrome is a well-recognized complication of shunt-dependent hydrocephalus. While SVS is considered a rare complication of CSF shunting, ${ }^{3,20}$ patients with SVS undergo a disproportionate share of shunt revisions. The precise definition of SVS is probably physician and/or institution dependent. Using chronic ICP monitoring data, Rekate has described 5 different classifications of the condition, which include intracranial hypotension, intermittent proximal obstruction with small ventricles, shunt failure without ventricular enlargement, increased ICP with a working shunt, and shunt-related migraine..$^{19,20}$ For the current survey, SVS was defined as symptomatic intermittent ICP elevation with small ventricle sizes. This definition is commonly used in the literature and considered to be the most common variant among the subclassifications proposed by Rekate.

As with proximal shunt obstruction, there is a wide range of opinions about the cause of SVS. Some respondents suggest that overdrainage is a central mechanism, but others inculpate altered compliance and duration of shunting. Data from the present survey indicate that most surgeons diagnose the condition with the assistance of ICP monitoring. Treatment philosophy among respondents generally involves, in order of preference, shunt revision 
and ASD placement, followed by ETV and cranial expansion. Yet, given the complexity of caring for these patients, practice patterns are difficult to compare and quite variable.

\section{Study Limitations}

This opinion-based survey has several limitations. Respondents represent only a portion $(64 \%)$ of the ASPN membership. Accordingly, presented findings are subject to nonresponse bias. Additionally, the reported philosophies and management styles represent those of boardcertified pediatric neurosurgeons predominantly practicing at large medical centers. Thus, the data and opinions may or may not reflect all North American pediatric neurosurgical care. Furthermore, despite efforts to create clear and objective questions, the words and phrases in the questionnaire could have been interpreted differently by respondents. Importantly, multiple-choice questions in the survey included a limited number of options, which underestimates the complexity of these clinical issues. While optional free-text boxes were included for most questions, only a few surgeons used this feature. Lastly, interpreting clinical management questions is challenging, especially since, in the absence of evidence-based guidelines, most surgeons provide individualized approaches to their patients' care. Despite these limitations, the study provides an overview of expert attitudes and opinions on shuntdependent hydrocephalus and highlights the need to improve our understanding and management of these critical problems. Accordingly, the discrepancies illustrated in this report should be considered in the design of future studies and registries.

\section{Conclusions}

The present survey of a representative group of experienced North American pediatric neurosurgeons shows wide variability in the understanding and management of shunt-dependent hydrocephalus and its complications. These discrepancies appear to originate from a lack of high-quality evidence and inconsistent knowledge of the existing literature. Notably, while most respondents intimate that choroid plexus is the tissue responsible for most ventricular catheter obstructions, the literature suggests that this occurs rarely. And while respondents often relegate chronic headaches in shunt patients to medical reasons, there is no literature available to support these opinions. Most importantly, the cause of proximal shunt obstruction, the treatment of chronic overdrainage, and the etiology of and best management for SVS remain altogether unresolved.

\section{References}

1. Baird LC, Mazzola CA, Auguste KI, Klimo P Jr, Flannery AM: Pediatric hydrocephalus: systematic literature review and evidence-based guidelines. Part 5: Effect of valve type on cerebrospinal fluid shunt efficacy. J Neurosurg Pediatr 14 (Suppl 1):35-43, 2014

2. Blegvad C, Skjolding AD, Broholm H, Laursen H, Juhler M: Pathophysiology of shunt dysfunction in shunt treated hydrocephalus. Acta Neurochir (Wien) 155:1763-1772, 2013

3. Browd SR, Gottfried ON, Ragel BT, Kestle JR: Failure of cerebrospinal fluid shunts: part II: overdrainage, loculation, and abdominal complications. Pediatr Neurol 34:171-176, 2006

4. Browd SR, Ragel BT, Gottfried ON, Kestle JR: Failure of cerebrospinal fluid shunts: part I: Obstruction and mechanical failure. Pediatr Neurol 34:83-92, 2006

5. Cheok S, Chen J, Lazareff J: The truth and coherence behind the concept of overdrainage of cerebrospinal fluid in hydrocephalic patients. Childs Nerv Syst 30:599-606, 2014

6. Collins P, Hockley AD, Woollam DH: Surface ultrastructure of tissues occluding ventricular catheters. J Neurosurg 48:609-613, 1978

7. Czernicki Z, Strzałkowski R, Walasek N, Gajkowska B: What can be found inside shunt catheters. Acta Neurochir Suppl 106:81-85, 2010

8. Drake JM, Kestle JR, Milner R, Cinalli G, Boop F, Piatt J Jr, et al: Randomized trial of cerebrospinal fluid shunt valve design in pediatric hydrocephalus. Neurosurgery 43:294-305, 1998

9. Dykema J, Jones NR, Piché T, Stevenson J: Surveying clinicians by web: current issues in design and administration. Eval Health Prof 36:352-381, 2013

10. Faulhauer K, Schmitz P: Overdrainage phenomena in shunt treated hydrocephalus. Acta Neurochir (Wien) 45:89-101, 1978

11. Hakim S: Observations on the physiopathology of the CSF pulse and prevention of ventricular catheter obstruction in valve shunts. Dev Med Child Neurol Suppl 20:42-48, 1969

12. Hanak BW, Ross EF, Harris CA, Browd SR, Shain W: Toward a better understanding of the cellular basis for cerebrospinal fluid shunt obstruction: report on the construction of a bank of explanted hydrocephalus devices. J Neurosurg Pediatr 18:213-223, 2016

13. Harris CA, McAllister JP II: What we should know about the cellular and tissue response causing catheter obstruction in the treatment of hydrocephalus. Neurosurgery 70:15891602,2012

14. Harris CA, Resau JH, Hudson EA, West RA, Moon C, Black $\mathrm{AD}$, et al: Effects of surface wettability, flow, and protein concentration on macrophage and astrocyte adhesion in an in vitro model of central nervous system catheter obstruction. J Biomed Mater Res A 97:433-440, 2011

15. Kestle JR, Drake JM, Cochrane DD, Milner R, Walker ML, Abbott R III, et al: Lack of benefit of endoscopic ventriculoperitoneal shunt insertion: a multicenter randomized trial. J Neurosurg 98:284-290, 2003

16. Kestle J, Drake J, Milner R, Sainte-Rose C, Cinalli G, Boop F, et al: Long-term follow-up data from the Shunt Design Trial. Pediatr Neurosurg 33:230-236, 2000

17. Koga H, Mukawa J, Nakata M, Sakuta O, Higa Y: Analysis of retained ventricular shunt catheters. Neurol Med Chir (Tokyo) 32:824-828, 1992

18. Pudenz RH, Foltz EL: Hydrocephalus: overdrainage by ventricular shunts. A review and recommendations. Surg Neurol 35:200-212, 1991

19. Rekate HL: Classification of slit-ventricle syndromes using intracranial pressure monitoring. Pediatr Neurosurg 19:1520, 1993

20. Rekate HL: Shunt-related headaches: the slit ventricle syndromes. Childs Nerv Syst 24:423-430, 2008

21. Rekate HL, Kranz D: Headaches in patients with shunts. Semin Pediatr Neurol 16:27-30, 2009

22. Sarkiss CA, Sarkar R, Yong W, Lazareff JA: Time dependent pattern of cellular characteristics causing ventriculoperitoneal shunt failure in children. Clin Neurol Neurosurg 127:30-32, 2014

23. Sekhar LN, Moossy J, Guthkelch AN: Malfunctioning ventriculoperitoneal shunts. Clinical and pathological features. J Neurosurg 56:411-416, 1982 
24. Singh D, Saxena A, Jagetia A, Singh H, Tandon MS, Ganjoo P: Endoscopic observations of blocked ventriculoperitoneal (VP) shunt: a step toward better understanding of shunt obstruction and its removal. Br J Neurosurg 26:747-753, 2012

25. Sklar FH, Nagy L, Robertson BD: The use of abdominal binders to treat over-shunting headaches. J Neurosurg Pediatr 9:615-620, 2012

26. Stein SC, Guo W: Have we made progress in preventing shunt failure? A critical analysis. J Neurosurg Pediatr 1:40-47, 2008

\section{Disclosures}

The authors report no conflict of interest concerning the materials or methods used in this study or the findings specified in this paper.

\section{Author Contributions}

Conception and design: all authors. Acquisition of data:
Kraemer. Analysis and interpretation of data: Iskandar, Kraemer. Drafting the article: Kraemer. Critically revising the article: Iskandar, Kraemer, Sandoval-Garcia. Reviewed submitted version of manuscript: all authors. Statistical analysis: Kraemer. Administrative/technical/material support: Kraemer. Study supervision: Iskandar.

\section{Supplemental Information \\ Online-Only Content}

Supplemental material is available with the online version of the article.

Questionnaire. https://thejns.org/doi/suppl/10.3171/2017.2. PEDS16265.

\section{Correspondence}

Bermans J. Iskandar, Department of Neurosurgery, University of Wisconsin Hospitals and Clinics, 600 Highland Ave., K4/832, Madison, WI 53792. email: iskandar@neurosurgery.wisc.edu. 